\title{
QUALIDADE DE VIDA NO AMBIENTE ESCOLAR COMO COMPONENTE DA FORMAÇÃO DO CIDADÃO: DESEJOS E CARÊNCIAS NO ESPAÇO FÍSICO
}

\author{
Ana Claudia Silveira Ribeiro ${ }^{1}$, Gisele Lángaro Soares ${ }^{1}$, Ticiana Fagundes da Porciuncula de Vilhena ${ }^{1}$, \\ Julianne Marçal Munhoz ${ }^{1}$, Valdir Marcos Stefenon² \\ ${ }^{1}$ Especialista em Educação pelo Programa de Pós Graduação lato sensu Educação: Interdisciplinaridade e \\ Transversalidade, Universidade Federal do Pampa, Campus São Gabriel \\ giselelangaro@yahoo.com.br \\ 2 Professor Adjunto, Universidade Federal do Pampa, Campus São Gabriel \\ valdirstefenon@unipampa.edu.br
}

\section{RESUMO}

O efetivo aprendizado escolar está relacionado, entre outros fatores, a qualidade de vida dos alunos, tanto dentro como fora da escola. Neste sentido, o espaço físico escolar possui grande importância para o corpo discente, uma vez que será cenário diário de estudos, discussões, debates, reflexões, convívios sociais e lazer. Nesta perspectiva, faz-se necessário caracterizar os aspectos relacionados à estrutura física da escola de modo a identificar intervenções que possibilitem uma melhoria na qualidade de vida dentro da mesma. $\mathrm{O}$ objetivo central do presente estudo foi investigar os aspectos relacionados à estrutura física de uma escola da rede pública de São Gabriel, RS utilizando-os como indicadores da qualidade de vida na escola. Foi aplicado um questionário para as turmas da pré-escola a $8^{a}$ séries do ensino fundamental contendo questões dirigidas relativas à qualidade das instalações disponibilizadas pela escola. Os resultados demonstraram que as necessidades dos estudantes da pré-escola são distintas daquelas dos estudantes da 4a a 8a séries. Entretanto para ambas as faixas etárias verificou-se a necessidade de espaços recreativos que respeitem uma das características mais marcantes das crianças que vem a ser a mobilidade elevada.

Palavras chave: estrutura física, ambiente escolar, rede pública de ensino, São Gabriel

\section{ABSTRACT}

The effective learning at school is related, among other factors, to the students' quality of life inside and/or outside school. The school's physical spaces present a great importance for the students since this is the place where they study, discuss, debate, reflect, interact and relax. In this scenario, it is necessary to characterize the aspects related to the physical structure in order to identify the interventions that can possible improve the life quality at school. The aim of this work was to investigate the aspects related to the physical structure of a public school located in São Gabriel, RS and using this diagnose as indicator of life quality at school. A questionnaire was applied to the preschool to eighth grades with questions related to the quality of the school's physical space. The results demonstrated that the preschool, first and third grades presented different needs than the fourth to eighth grades. However, a clear necessity of recreational spaces was detected in all grades. Those spaces should respect the most important characteristic of a kid: it's extremely high mobility.

Keywords: physical structure, school environment, public school, São Gabriel 


\section{INTRODUÇÃO}

A chegada do século XXI trouxe mudanças na sociedade, nas relações humanas e no mercado de trabalho. A escola, entretanto, parece ser a que menos sofreu tais mudanças. Muitos passam por ela, mas pouco intervém de maneira positiva para o seu aprimoramento. Essas instituições educacionais não deveriam ficar alheias a essas mudanças, já que precisam desempenhar um papel social de alta relevância. A transformação, não só do sistema educacional, mas da sociedade, tem de passar pela escola. Neste contexto, é preciso que um novo sentido de cidadania seja construído (FICAGNA e ORTH, 2010).

Mudanças sociais relevantes podem começar pela escola, partindo do princípio de que todos passam (ou deveriam passar) por ela, pois as grandes transformações não se originam apenas de grandes feitos, mas de iniciativas do dia-a-dia, simples e persistentes. É essencial que a escola desperte nos alunos a capacidade de compreenderem e atuarem no mundo em que vivem. É preciso dar-lhes informações e formação para que possam atuar como cidadãos, organizando-se e defendendo seus interesses e da coletividade. Precisam, porém, aprender a respeitar regras, leis e normas estabelecidas (FICAGNA e ORTH, 2010).

Ao repensarem seu ambiente escolar e como podem atuar positivamente sobre ele, os alunos estarão também repensando o mundo em que vivem. Ao serem inseridos nesse processo passarão a valorizar o seu meio, pois, se sentirão como sujeitos transformadores. Como bem diz Freire "meu papel no mundo não é só o de quem constata o que ocorre, mas também o de quem intervém como sujeito de ocorrências. Não sou apenas objeto da História, mas seu sujeito igualmente" (1996, p. 85). E completa afirmando que é preciso que constatemos a realidade, não somente para nos adaptarmos, mas para mudarmos. Essa constatação não nos levará à impotência, mas ao desejo de transformar (FREIRE, 1996).

O efetivo aprendizado escolar está relacionado a diversos fatores. A qualidade de vida dos alunos, tanto dentro como fora da escola, pode ser citada como um destes fatores já que pode interferir diretamente no aprendizado. A realidade observada previamente em escolas de Educação Básica do município de São Gabriel revela que o ambiente escolar de algumas instituições deixa a desejar no que se refere às condições consideradas adequadas para uma vivência e convivência saudáveis no que diz respeito desde as condições físicas do ambiente até o comportamento, hábitos e atitudes, dos alunos. Este fato, por sua vez, aponta a necessidade de uma intervenção objetivando mudanças.

Nesta perspectiva, faz-se necessário caracterizar os aspectos relacionados à estrutura física da escola de modo a identificar intervenções que possibilitem uma melhora na qualidade de vida dentro das mesmas. Esta pesquisa foi desenvolvida em uma escola da rede pública de São Gabriel, RS, com alunos do Ensino Fundamental, durante o ano letivo de 2011. Foram aplicados questionários e realizadas atividades lúdicas e observações do comportamento dos educandos, de modo a levantar as opiniões e atitudes dos mesmos a respeito dos aspectos abordados. O objetivo central do trabalho foi investigar os aspectos relacionados à estrutura física da escola como indicadores da qualidade de vida na escola dos sujeitos envolvidos no espaço escolar.

\section{QUALIDADE DE VIDA NO AMBIENTE/ESPAÇO FÍSICO ESCOLAR}

A idéia de qualidade de vida depende de diversos fatores. A Organização Mundial da Saúde (OMS) definiu como qualidade de vida "a percepção do indivíduo de sua posição na vida, no contexto da cultura e sistema de valores nos quais ele vive e em relação aos seus objetivos, 
expectativas, padrões e preocupações" (MINAYO et al., 2000). Estes autores afirmam, ainda, que "qualidade de vida é uma noção eminentemente humana, que tem sido aproximada ao grau de satisfação encontrado na vida familiar, amorosa, social e ambiental e à própria estética existencial." A qualidade de vida deveria estar presente em todos os ambientes, mas na escola ela se faz ainda mais necessária, pois, é onde o sujeito é preparado para viver em sociedade e aprende a aprimorar o mundo onde vive. Mas, esse processo de ensino-aprendizagem só ocorrerá em sua plenitude se o ambiente em que ele é realizado apresentar as condições adequadas para que isto aconteça.

Tal ambiente denominado espaço físico escolar possui grande importância para o corpo discente, uma vez que este será cenário diário de estudos, discussões, debates, reflexões, convívios sociais e lazer. Espaço que deve ser convidativo, representando relações de intimidade e afetividade. Para melhor compreender as contribuições deste espaço físico ao desenvolvimento e aprendizagem, devemos levar em consideração que:

Para qualquer ser vivo, o espaço é vital, não apenas para a sobrevivência, mas, sobretudo para o seu desenvolvimento. Para o ser humano, o espaço, além de ser um elemento potencialmente mensurável, é o lugar de reconhecimento de si e dos outros, porque é no espaço que ele se movimenta, realiza atividades e estabelece relações sociais (LIMA, 1995, p. 187).

Tanto o ato de ensinar como o de aprender exigem condições propícias ao bem estar do docente e do discente tornando-se um espaço de possibilidades ou de limites. Possibilitar um ambiente facilitador para o desenvolvimento social estabelece ou restabelecer valores como preservação e valorização de um espaço público. Contribui também para que os envolvidos possam sentir-se confortáveis e consigam reconhecê-lo como um lugar que lhes pertence.

Estudos revelam que o ambiente físico, determina, em grande parte, as experiências da criança, seu aprendizado e desenvolvimento. Embora a qualidade de vida e a qualidade do ambiente não dependam apenas das características físicas, estas tem papel muito importante.

\footnotetext{
Espaços e tempos fazem parte da ordem social escolar. Sendo assim, são sempre pessoais e institucionais, individuais e coletivos, e a busca de delimitá-los, controlá-los, materializando-os em quadros de anos/séries, horários, relógios, campainhas, ou em salas específicas, pátios, carteiras individuais ou duplas, deve ser compreendida como um movimento que teve ou propôs múltiplas trajetórias de institucionalização da escola. Daí, dentre outros aspectos, a sua força educativa e sua centralidade no aparato escolar (ESCOLANO 2001, p.27).
}

Outros autores reafirmam a importância do espaço físico como uma ferramenta pedagógica. Lima (1998) diz que todo espaço produzido pelo homem interfere no processo educativo de forma positiva ou negativa. O espaço condiciona nossos gestos diários, habitua nossa visão, estimula elementos simbólicos, estabelece pontos de referência. Se a escola não oferece espaço adequado, tratado com cuidado estético, com áreas verdes e agradáveis aos sentidos, à criança se sentirá estimulada a desenvolver relações saudáveis e equilibradas com o ambiente, com o outro e consigo mesma? Piaget, em suas teorias sobre a psicogênese das estruturas topológicas na infância, remete à valorização das primeiras experiências espaciais como fatores determinantes do desenvolvimento sensorial, motor e cognitivo (FRAGO E ESCOLANO, 2001). A escola deveria, diante deste entendimento, ser espaço rico em termos de estímulos para experiências espaciais, oferecendo toda uma infraestrutura compatível com o desenvolvimento 
global do aluno. Para Hunger et al (2004) a arquitetura tem sido uma barreira para o trabalho pedagógico numa perspectiva inclusiva.

Em contra partida, o caderno Lições do Rio Grande (2009) nos revela que muitas escolas estaduais se encontram em condições adequadas, devido à participação ativa de seus professores e às equipes de direção que conseguiram se mobilizar e mobilizar suas comunidades. Muitas vezes a falta de estrutura física escolar passa pelo descaso. Vago (1999) destaca esse papel de intervenção possível dos professores, que como sujeitos sociais praticantes, de fato, participam ou deveriam participar também, da instituição e da consolidação de novas práticas escolares. Sugerindo que os docentes deveriam buscar mecanismos de intervenção, tanto no cotidiano, como em processos de discussões mais amplos no campo político e social. Assim como Freire (2000 p.37) nos lembra de nos tornarmos capazes de intervir na realidade, tarefa incomparavelmente mais complexa e geradora de novos saberes do que simplesmente a de nos adaptar a ela. O mesmo autor continua evidenciando esse papel com a frase "Ensinar exige a convicção de que a mudança é possível".

\section{NOSSA REALIDADE DO AMBIENTE/ESPAÇO FÍSICO ESCOLAR}

Este trabalho relata o estudo desenvolvido em uma escola pública do município de São Gabriel, RS, envolvendo alunos do Ensino Fundamental. Neste estudo, os aspectos relacionados à estrutura física da escola foram utilizados como indicadores da qualidade da vida escolar. Como ferramenta para quantificar e qualificar tais questões foi aplicado, no ano de 2011, um questionário para as turmas da pré-escola a 8 a séries do ensino fundamental contendo questões dirigidas relativas à qualidade das instalações disponibilizadas pela escola. Inicialmente, foi feito o levantamento de todos os espaços disponibilizados pela escola. Estes espaços existentes (Biblioteca, pracinha, refeitório, salas de aula, sala de informática) foram listados no questionário e a estes se somou os espaços usuais de uma escola os quais não faziam parte da atual estrutura da mesma (Quadra esportiva, horta, laboratório de ciências, sala de áudio vídeo, brinquedoteca e salas de aulas amplas e equipadas). Levando em consideração as limitações da leitura e escrita, na pré-escola, 1a e 3a séries, o questionário foi aplicado de forma oral com a utilização de plaquinhas (tá legal e não tá legal). Com as turmas da 2 a série não foi possível aplicar o questionário pela incompatibilidade de horários. Para as turmas de 4ạ a $8^{a}$ séries o mesmo questionário foi utilizado. Entretanto, solicitou-se que os estudantes classificassem a qualidade do ambiente atribuindo notas em uma escala de 1 a 6, sendo um (1) a nota máxima e seis (6) a mínima, para cada espaço listado no questionário. O questionário completo constou de 14 questões, porém neste trabalho, somente uma será discutida: "Para você uma escola de qualidade deveria ter".

Ao total foram abordados 116 alunos, sendo 71 de 4a a 8a série e 45 da pré-escola, 1a e 3a séries. Nas turmas de 4a a $8^{a}$ series, a faixa etária era entre nove e 21 anos. Do número total de alunos $72 \%$ eram meninos e $53 \%$ meninas. Nas turmas de pré-escola, 1a e 3a séries, $51 \%$ eram meninos e $49 \%$ meninas com faixa etária entre 5 a 10 anos.

Quando questionados, para você uma escola de qualidade deveria ter: (Enumere as alternativas sendo 1 o mais importante e 6 o menos importante em sua opinião), 58\% dos alunos escolheram quadra esportiva como o item mais importante, seguido por $14 \%$ salas amplas e equipadas e $14 \%$ sala de informática. (Figura 1). 


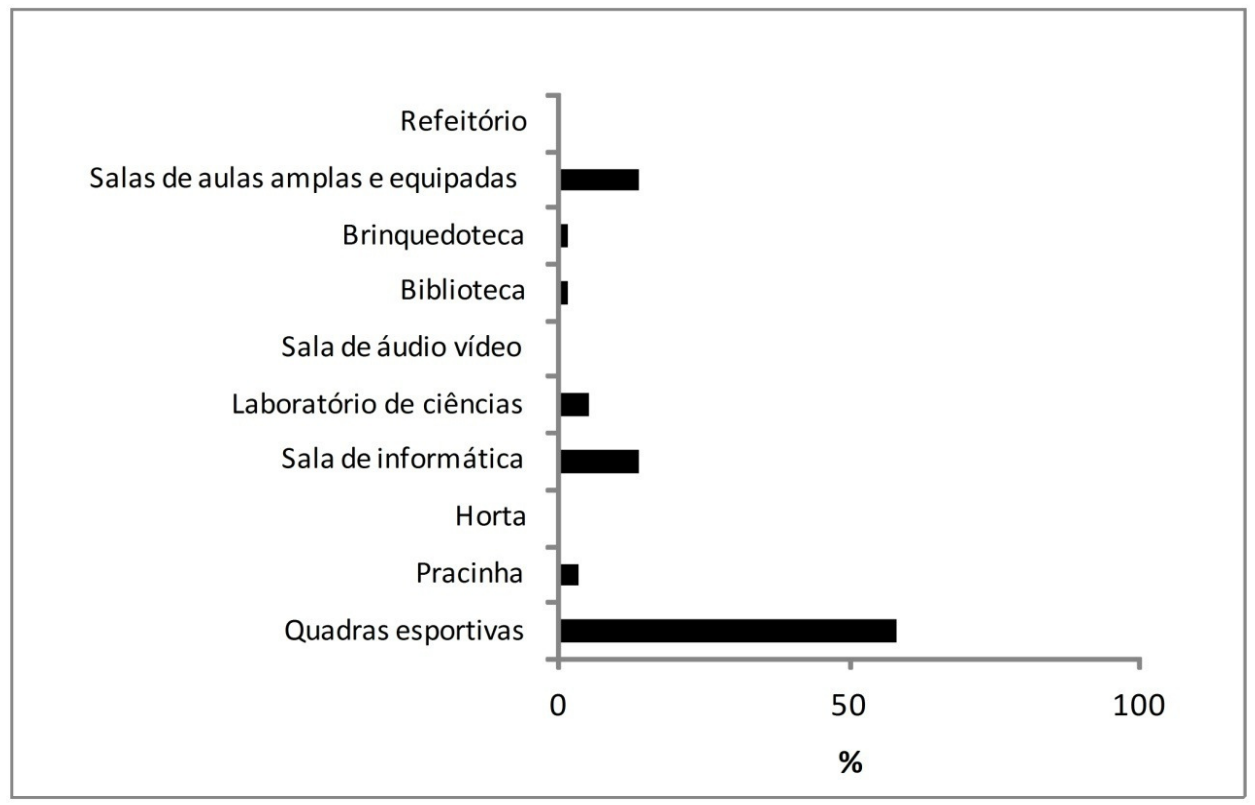

Figura 1. Espaços considerados como mais importantes para a qualidade de vida no ambiente escolar (score 1) pelas

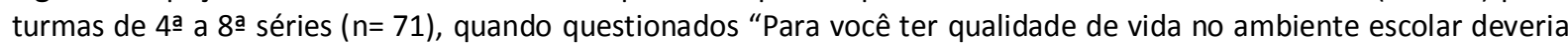
ter?".

Os resultados do questionário mostram o apelo dos meninos por um espaço adequado à prática de esportes, principalmente o futebol atualmente realizado numa praça pública da Cidade. Outro espaço considerado como mais importante foi relacionado a salas amplas e equipadas. A escola funciona em uma edificação antiga usada para fins habitacionais e adaptada para as necessidades atuais. Por conta disso às salas são pequenas, algumas não tem cortinas o que nos dias de sol tornam a aulas mais difíceis. Dentro deste espaço o quadro negro foi um dos itens mais citados nas sugestões de melhorias. Juntamente com as salas amplas e equipadas, a sala de informática foi outro espaço com número representativo de respostas com escore 1. A escola já havia recebido computadores há alguns meses, até o momento tinham o local, mas ainda estavam à espera de mão de obra especialidade para a instalação. Entre os alunos entrevistados apenas $4 \%$ consideraram a pracinha como espaço importante para a qualidade de vida no ambiente escolar. Entretanto, durante o debate dos questionários a pracinha foi lembrada por muitos alunos. A pracinha que existe na escola esta em péssimas condições de conservação e de segurança. Espaços como sala de vídeo, horta e refeitório não foram assinalados por nenhum dos alunos questionados como sendo importante para a qualidade de vida na escola. A sala de vídeo e a horta faziam parte da lista de espaços que não estavam presentes na atual estrutura da escola enquanto que o refeitório fazia parte da estrutura já pertencente à escola.

Para as turmas da pré-escola, 1a e 3a séries, quando questionadas sobre o que está legal e o que não está legal em sua escola, $89 \%$ dos alunos indicaram que a pracinha não estava legal. A quadra de esportes foi lembrada por $62 \%$ dos alunos como um ambiente que não estava legal e $51 \%$ dos alunos consideraram a sala de informática como um ambiente que não estava adequado. Já com relação às salas amplas e equipadas, estas não foram apontadas pela maioria dos estudantes como uma estrutura que estivesse inadequada já que apenas $38 \%$ dos alunos responderam que esta estrutura física não estava adequada (Figura 2). Apesar deste resultado, tal espaço foi observado por sua carência em relação às turmas da pré-escola, onde a sala de aula 
apresenta-se inadequada para a faixa etária, pelo tamanho, organização, improvisação e qualidade dos materiais.

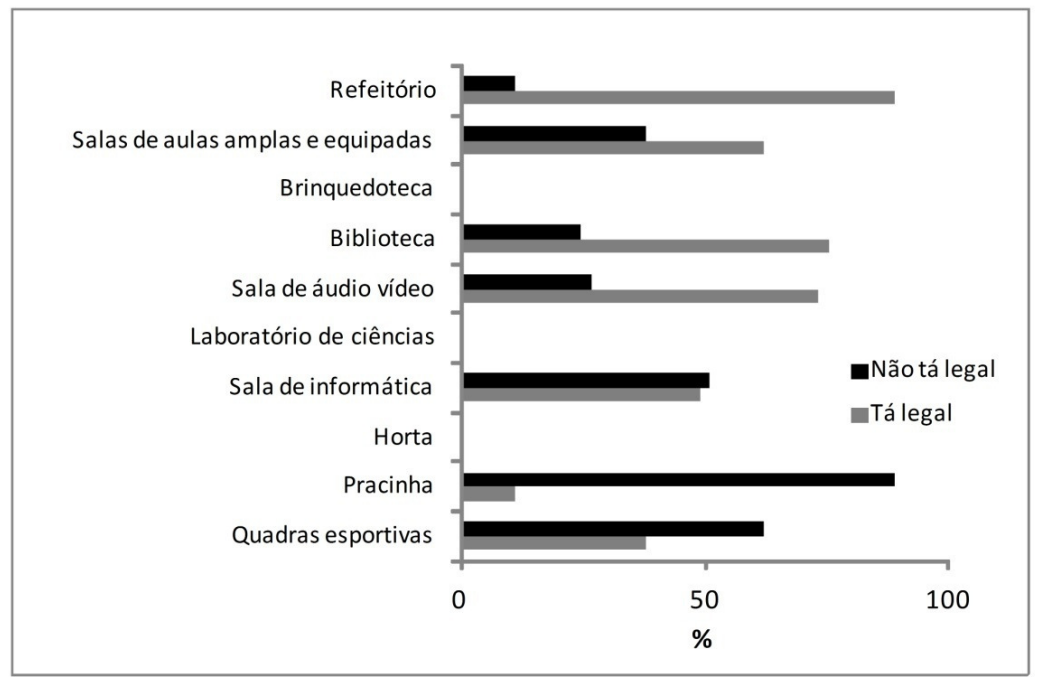

Figura 2. Espaços considerados importantes para a qualidade de vida no ambiente escolar que estão legal e não estão legal para as turmas da pré-escola, 1a e 3a séries $(n=45)$, quando questionados "Para você o que está legal e o que não está legal em sua escola?".

Com base nos resultados da pesquisa verifica-se que as necessidades dos estudantes das séries iniciais são distintas daquelas dos estudantes das séries finais. Tal afirmativa torna-se evidente ao observar a importância da pracinha para a maioria dos estudantes das séries iniciais (Figura 2) e a não importância deste mesmo espaço para os das séries finais (Figura 1). Embora se saiba que as necessidades distintas de espaço entre os estudantes de diferentes faixas etárias, verificou-se que para ambos, as quadras esportivas foram apontadas pela maioria como um espaço importante que na qual se apresentava inadequado. Este é um dos aspectos que Freire (1989) critica na educação institucionalizada. A escola submete a criança há uma imobilidade excessiva, que desrespeita sua "marca característica", ele continua dizendo que a escola não deve apenas mobilizar a mente, mas também o corpo. "O corpo e a mente devem ser entendidos como componentes que integram um único organismo. Ambos devem ter assento na escola" (1989, p. 13).

Após o levantamento feito com os alunos houve a divulgação e discussão dos resultados

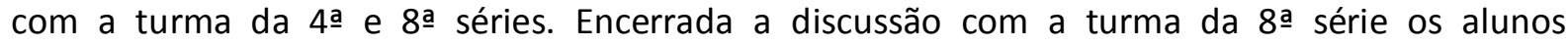
sinalizaram algumas alternativas de intervenção que auxiliassem na melhoria da qualidade do ambiente escolar. Foram confeccionados cartazes e a turma foi dividida em grupos. Assim cada grupo visitou uma turma do turno da manhã com o objetivo de conscientizar os demais alunos quanto à conservação da limpeza das salas e banheiros, conservar a mobília escolar, a importância da separação do lixo e sua reciclagem, posturas positivas para preservar o ambiente mais harmonioso como respeito a colegas, professores e funcionários. Atitudes que, apesar da precariedade do espaço físico escolar, poderiam conservar a estrutura existente não agravando a situação do local. 


\section{CONSIDERAÇÕES FINAIS}

A estrutura física da escola, assim como sua organização, manutenção e segurança revelam muito sobre aqueles que ali vivem. A necessidade de uma instituição de ensino bem estruturada é de fundamental importância para as capacidades físicas, intelectuais e morais dos discentes. Um espaço acolhedor transforma o aprendizado em uma ferramenta estimuladora e, cria condições para que o ato educativo possa ser refletido no desenvolvimento bio-psico-social. As pesquisas de Moore (1992) comprovam que, quando as crianças ficam em espaços muito restritos, os comportamentos tornam-se mais agressivos, destrutivos e a interação diminui. Rosa e Galera (2011) citam Michel Foucalt quando este diz que a "docilização" produz um tipo de sociedade que favorece a uma teia de interesses e poder criando uma relação de submissão e disciplinação. Assim, o processo de transformação que poderia ocorrer a partir da escola fica enfraquecido e perdemos o sentido de pertencer. Podemos então, ainda segundo Focault (apud ROSA e GALERA, 2011) entender porque os alunos picham paredes, quebram a mobília da escola, sem deixar sua marca positiva. Os resultados desta pesquisa demonstram que os estudantes tem consciência das deficiências de sua escola reafirmam a constatação que deu origem a este estudo de que a qualidade de vida na instituição deixa a desejar no que se refere às condições consideradas adequadas para uma vivência e convivência saudáveis e requer intervenção visando à melhoria das condições físicas da escola.

\section{REFERÊNCIAS BIBLIOGRÁFICAS}

FICAGNA, Marisa Fracalossi; ORTH, Miguel Alfredo. Educação para um novo cidadão: construindo possibilidades ou relações entre a teoria e a prática. In: ANDREOLA, Balduino Antonio et al. (orgs). Formação de educadores: da itinerância das universidades à escola itinerante. Ijuí: Ed. Unijuí, 2010. p. 247-259.

ESCOLANO, Agustín. Arquitetura como programa: espaço-escola e currículo. In: VIÑAO FRAGO, Antonio; ESCOLANO, Agustín. Currículo, espaço e subjetividade: a arquitetura como programa. Tradução: Alfredo Veiga-Neto. 2. ed. Rio de Janeiro: DP\&A, p. 19-57, 201.

FRAGO, Antonio V.; ESCOLANO, Agustín. Currículo, espaço e subjetividade: a arquitetura como programa. Rio de Janeiro: DP\&A Editora, 2001.

FREIRE, J.B. Educação Física de corpo inteiro. Teoria e prática da educação física escolar. Rio de Janeiro, Editora Scipione, p.13, 1989.

FREIRE, Paulo Pedagogia da indignação: caratas pedagógicas e outros escritos. São Paulo Ed. UNESP 2000. p.37.

. Pedagogia da autonomia: saberes necessários à prática educativa. 6. ed. São Paulo: Paz e Terra, p. 85, 1996.

HUNGER, D; SQUARCINI, C.R; PEREIRA, J.M. A Pessoa portadora de deficiência física e o lazer. Revista Brasileira de Ciências do Esporte. Campinas, Autores Associados. v. 25, 2004.

LIMA, M. W. S. Arquitetura e educação. São Paulo, Studio Nobel, p.187, 1995.

. Espaços Educativos: usos e construções. Brasília, MEC, 1998.

MINAYO, Maria Cecília de Souza; HARTZ, Zulmira Maria de Araújo; BUSS, Paulo Marchiori. Qualidade de vida e saúde: um debate necessário. Ciência e Saúde Coletiva, v. 5, n. 1, p. 7-18, 2000. 
MOORE, G.T. Transformation in the architecture o childcare; theory, research and design applications. In: IAPS 12 International Conference Proceedings. Marmaas Chaldikiki, Gce, 1992.

RIO GRANDE DO SUL. Referencial Curricular: Lições do Rio Grande: Linguagens Códigos e suas Tecnologias Artes e Educação Física. Secretaria de Educação do Estado. Porto Alegre, v.2, p.6, 2009.

ROSA, Eloisa Helena da; GALERA; Joscejy Bassetto. A gestão do espaço físico escolar: um desafio social. Disponível em: <http://www.diaadiaeducacao.pr.gov.br/portals/pde/arquivos/1699-8.pdf>. Acesso em: 2 jul. 2011.

VAGO, T. M. Início e fim do século XX: Maneiras de fazer educação física na escola. Campinas, Cadernos CEDES, vol.19, n.48, p.31-50, 1999. 